\title{
The association of asthma education centre characteristics on hospitalizations and emergency department visits in Ontario: a population-based study
}

Nancy J Garvey', Therese A Stukel ${ }^{2,5}$, Jun Guan², Yan Lu², Phillip T Bwititi ${ }^{1}$ and Astrid Guttmann ${ }^{2,3,4,5^{*}}$

\begin{abstract}
Background: International guidelines recommend patient education as an essential component of optimal asthma management. Since 1990 hospital-based asthma education centres (AECs) have been established in Ontario, Canada. It is unknown whether patient outcomes are related to the level of services provided.

Methods: Using linked, population-based health administrative and hospital survey data we analyzed a population of patients aged 2 to 55 years with a hospitalization for asthma ( $N=12$ 029) or a high acuity asthma emergency department (ED) visit ( $N=63$ 025) between April 2004 and March 2007 and followed for three years. Administrative data documenting individuals' attendance at AECs were not available. Poisson models were used to test the association of potential access to various AEC service models (outpatient service availability and in-hospital services) with asthma readmissions, ED visits or death within 6 to 36 months following the index admission or ED visit.

Results: Fifty three of 163 acute care hospitals had an AEC $(N=36)$ or had access by referral $(N=17)$. All AECs documented use with guideline-based recommendations for AE programs. ED patients having access to an AEC that offered full-time, extended hours had reduced rates of adverse outcomes (adjusted relative rate [aRR] 0.78, $95 \%$ confidence interval $[\mathrm{CI}] 0.69,0.90)$ compared to those with no AEC access. Hospitalized patients with access to asthma education during hospitalization had reduced rates of adverse events (aRR 0.87, 95\% Cl 0.75, 1.00) compared to those with no inhospital AEC access.
\end{abstract}

Conclusion: Although compliant with asthma guideline-based program elements, on a population basis access to asthma education centres is associated only with a modest benefit for some admitted and ED patients and depends on the level of access to services provided. Review of both services provided and strategies to address potential barriers to care are necessary.

Keywords: Asthma, Asthma education, Hospitalizations, Emergency department visits, Outcomes

\footnotetext{
* Correspondence: astrid.guttmann@ices.on.ca

${ }^{2}$ Institute for Clinical Evaluative Sciences, Toronto, Ontario, Canada

${ }^{3}$ Division of Paediatric Medicine, Hospital for Sick Children, Toronto, Ontario, Canada
}

Full list of author information is available at the end of the article 


\section{Background}

Approximately 1.7 million of the 13 million children and adults in Ontario have been diagnosed with asthma, with the associated economic burden in 2011 estimated to be over $\$ 1.8$ billion Canadian dollars [1]. Clinical practice guidelines for asthma recommend patient education as essential to optimize associated health outcomes and reduce healthcare costs [2-4]. To address this need in Ontario, Canada, over 30 hospital-based asthma education centres (AECs) were established between 1990 and 2004, funded through hospital global budgets and/or through industry contributions. AECs were tasked to integrate guideline-based patient education standards and specialized counseling skills into programs for adults, children and caregivers.

The Canadian Network for Respiratory Care originated in 1994 to address the growing need for specialized asthma education skills, knowledge and ability. A national certification program for the Certified Asthma Educator designation was established in 1999 [5], incorporating standards for guideline-based program content [2-4] and specialized training for staff. Key elements of asthma education included diagnosis, medications, inhaler devices, prevention of symptoms and attacks, signs of worsening asthma, monitoring asthma control, and need for medical attention [2]. Although clinical trials have shown asthma education to be effective in improving disease control [6-12], to our knowledge, there have not been any population-based studies on the effectiveness of multifaceted, hospital-based asthma education programs.

The aims of this study were to (i) describe the attributes of AECs in Ontario including education program and service availability characteristics, and (ii) assess whether patients hospitalized with asthma or having an emergency department (ED) visit for asthma with access to AECs had improved outcomes compared to those without access. We hypothesized that access to AECs with fulltime and extended hours for outpatient care, and asthma education during an admission or ED visit would be associated with reduced readmissions and ED visits.

\section{Methods}

We undertook a retrospective population-based cohort study of patients with asthma seen in an acute care hospital or ED in Ontario, Canada between April 1, 2004 and March 31, 2007. Patients were followed for three years (through March 31, 2010). An AEC was a centre that provided a hospital-based program of asthma selfmanagement education to children and/or adults with asthma.The research was approved by the research ethics boards at Charles Sturt University, protocol number 2007/103 and Sunnybrook Health Sciences Centre, Project Identification Number 353-2009.

\section{Data sources}

\section{Survey data}

One hundred sixty three acute care hospitals in Ontario were contacted by phone to confirm AEC availability during 2004-2007. If the site was identified as potentially providing AEC service, an email including the study description, consent form and a link to an electronic survey was forwarded to the appropriate contact person. The survey was designed and beta tested based on a similar survey on diabetes patient education programs [13]. The survey identified onsite (primary) AECs and referral sites associated with the primary AEC, service delivery and guideline-based characteristics of the program.

AEC service characteristics included:

- Hours of operation: full-time ( $\geq 30 \mathrm{hrs}$./wk.), part-time $(<30 \mathrm{hr} . / \mathrm{wk}$.), regular (Monday through Friday $8 \mathrm{AM}$ to $4 \mathrm{PM}$ ) or extended (before $8 \mathrm{AM}$, after 4. PM and/or weekends) hours;

- AEC access at either a primary hospital site or by a pre-arranged referral relationship to a primary site; and

- Asthma education provided to inpatients and/or ED patients.

\section{Health administrative data}

Patient records were linked using unique, anonymized, encoded identifiers across multiple Ontario health administrative databases containing information on all publicly insured, medically necessary hospital and physician services. These included the Discharge Abstract Database for hospital admissions that includes the most responsible diagnosis for length of stay, secondary diagnosis codes, comorbidities present upon admission, and complications occurring during the hospital stay; the National Ambulatory Care Reporting System for ED visits; the Ontario Health Insurance Plan for physician billings that includes diagnosis codes; and the Registered Persons Database for patient demographic information and deaths. Neighborhood income was derived from Statistics Canada census estimates from 2006. Rurality was defined by patient postal code using the Rurality Index for Ontario (RIO) 2008 which accounts for population size and travel time [14].

\section{Study cohorts}

We divided our cohort into those with a first (index) (i) admission to hospital or (ii) high acuity ED visit for asthma between April 1, 2004 and March 31, 2007. Asthma was determined using the Most Responsible Diagnosis and based on the International Classification of Disease $10^{\text {th }}$ revision-Canada diagnosis codes of $\mathrm{J} 45$ (asthma); or R05 (cough) or R06 (abnormalities of breathing) with a secondary diagnosis of J45. High acuity ED visits were determined using the Canadian Triage Assessment Score 
(CTAS) levels 1-3 representing resuscitation, emergent, and urgent, respectively.

We excluded children under 2 and adults over 55 years of age to reduce the likelihood of other diagnoses that would likely not be cared for in an AEC (bronchiolitis in the young and chronic obstructive pulmonary disease in the elderly), patients transferred from other EDs, and those who did not survive 6 months after the index event.

\section{Outcomes}

The primary outcomes were readmission or high acuity ED visit for asthma or death from any cause during the 6 to 36 months after the index event to give patients a 6 month opportunity to access an AEC for follow up care (Figure 1). The primary exposure was access to an onsite or referral hospital-based AEC for outpatient follow up care at the time of the index event, categorized according to AEC service availability, defined as full-time or part-time, and having regular or extended hours of operation. The secondary exposure was asthma education availability to inpatients or ED patients. We could ascertain only whether the AEC service was available at the index hospital but not whether patients actually used the service.

Covariates included patient risk factors associated with asthma outcomes, including age [15], sex, [16] socioeconomic status [17], rural residence [18], history of asthma admissions or ED visits in the previous two years (as a measure of disease severity), and health services use in the two years prior to the index event including any primary care visit (as a proxy for access to primary care) and any specialist visit for asthma. We controlled for a history of asthma based on the Ontario Asthma Surveillance and Information System, a validated registry using administrative data to define incident and prevalent cases of asthma in Ontario [19]. We also controlled for hospital type: teaching, large community or small.

\section{Analysis}

We used Poisson regression to analyze the association between AEC access and outcomes, controlling for patient risk and accounting for clustering within the initial hospital using generalized estimating equation models $[20,21]$. Patient risk factors included age, sex, asthma prevalence, history of primary care and specialist visits, previous ED visits and hospitalizations for asthma, neighbourhood income quintile, rural residence and hospital type.

Secondary analyses tested the association between availability of inpatient or ED asthma education during the index event and the outcomes. SAS v9.2.1 was used for analyses [22].

\section{Results}

\section{Asthma education centres and survey data}

\section{Access to asthma education}

Of the 163 acute care facilities contacted by phone, 43 hospital corporations were identified as potentially meeting the definition of an AEC. Five were excluded as they did not provide an organized asthma education program and 5 did not provide access to an AEC for greater than one year during the study period. Of the remaining 33 , two did not reply.

Completed surveys from the other 31 hospital corporations documented the provision of hospital-based AEC services at 32 primary locations (one hospital site provided part-time primary services at two hospitals' locations). The 32 primary hospital sites received referrals from 17 associated hospitals. The 2 hospital corporations

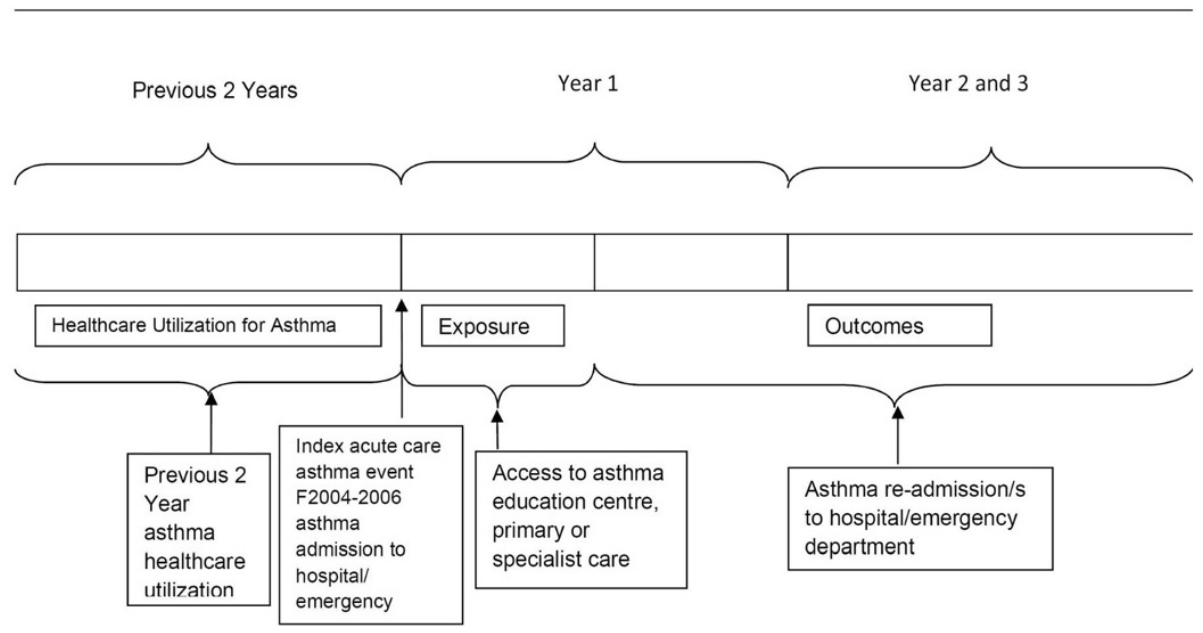

Figure 1 AEC Study: Index Visit and Main Exposure Timeframes. 
that did not reply had publicly available information on their AEC services for four primary hospital sites. This information included hours of operation, programs for children and adults, and access to inpatient and emergency department asthma education interventions. The public information was confirmed by Nancy Garvey with the appropriate Respiratory Therapy Directors.

In summary, there were 53 hospital-based AEC sites that consisted of 36 primary sites and 17 referral sites providing referrals to primary sites. 110 hospitals had no access to AEC services.

\section{Elements of asthma education programs}

The survey revealed all of the responding sites were compliant with guideline-based program elements with minor variations in 2 of 16, namely they did not include peak flow monitoring or behavior modification techniques (Table 1).

Table 1 Asthma education centre guideline-based program and service delivery characteristics for hospital-based AECs in Ontario

\begin{tabular}{|c|c|}
\hline Program characteristics & $\begin{array}{l}\text { Yes } \\
\mathrm{N}=32^{*}\end{array}$ \\
\hline \multicolumn{2}{|l|}{ Population served } \\
\hline Adults & $29(91 \%)$ \\
\hline Pediatrics/caregivers & $30(94 \%)$ \\
\hline Asthma education and resources provided in other languages & $7(22 \%)$ \\
\hline \multicolumn{2}{|l|}{ Guideline-based program characteristics } \\
\hline Patient assessment & $32(100 \%)$ \\
\hline Information provided about what asthma is & $32(100 \%)$ \\
\hline Identification of individual risk/trigger Factors & $32(100 \%)$ \\
\hline Review of asthma medications & $32(100 \%)$ \\
\hline Difference between "relievers" and "controllers" & $32(100 \%)$ \\
\hline Potential side effects of medications & $32(100 \%)$ \\
\hline Review of asthma medication administration techniques & $32(100 \%)$ \\
\hline Prevention of symptoms and attacks & $32(100 \%)$ \\
\hline Signs that suggest asthma is worsening & $32(100 \%)$ \\
\hline Coping strategies (e.g., how to deal with teachers/employers/healthcare professionals) & $32(100 \%)$ \\
\hline Monitoring control of asthma & $32(100 \%)$ \\
\hline Peak flow monitoring & $28(88 \%)$ \\
\hline Environmental control & $32(100 \%)$ \\
\hline How and when to seek medical attention & $32(100 \%)$ \\
\hline Written action plan & $32(100 \%)$ \\
\hline Behavior modification approach & $29(91 \%)$ \\
\hline
\end{tabular}

Human resources

Certified Asthma Educators

Other multi-disciplinary team members (Social Worker, Pharmacist)

\section{Hours of service}

Full-time regular hours (Monday through Friday 8AM to 4PM)

Full-time regular and extended hours (before 8AM, after 4 PM and/or weekends)

Part-time (less than 30 hrs. per week) regular hours

Part-time regular and extended hours

Inpatient or ED asthma education provided by AEC staff

Inpatient education

${ }^{*} \mathbf{N}=32$ primary sites with survey responses; $N=36$ primary sites with service delivery information in survey and/or in the public domain. 


\section{Study cohort}

After applying all exclusion criteria (Figure 2), the final cohort consisted of 75054 patients, 12029 with an index admission and 63025 with an index ED visit. Table 2 reports the baseline characteristics of the cohorts according to access to AEC service availability. Almost half (44\%) did not have access to AECs. Patient characteristics differed across AEC service availability groups. Patients with more severe asthma, based on prior hospital admissions and high acuity CTAS scores, tended to be seen in hospitals with fulltime extended hours AECs.

\section{Outcomes}

Overall, 8230 (24\%) of the ED cohort and 3569 (50\%) of the admission cohort had an asthma ED visit or admission in the 6-36 months following the index event.
Table 3 describes the outcomes for each cohort according to AEC service availability. For both cohorts, the percentage of patients with no subsequent ED visits was highest in the AEC full-time/extended hours group.

Adjusting for covariates, there was a reduced rate of ED visits or hospitalizations for ED patients with access to AECs that offered full time extended hours as compared with those having no access to an AEC: adjusted relative rate (aRR), 0.78 (95\% confidence interval (CI), 0.69 - 0.90) (Table 4). Access to asthma education services during the inpatient stay was associated with lower rates of admissions or ED visits for patients hospitalized with asthma (Table 5).

\section{Discussion}

Hospital-based AECs in Ontario have been implemented locally through hospital's global budgets and/or industry-

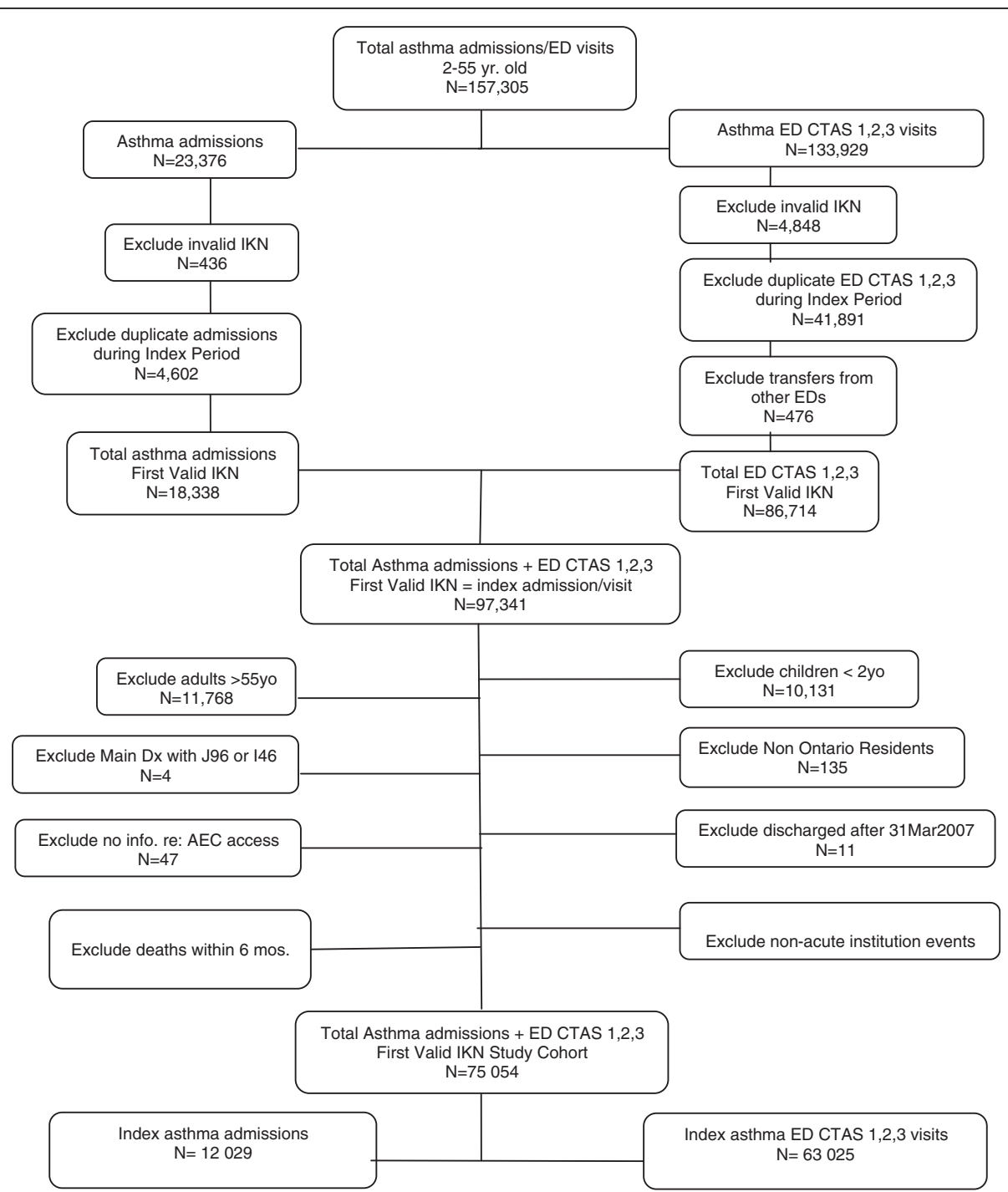

Figure 2 Identification of Study Cohort April 1, 2004 through March 31, 2007. *|KN = a unique anonymous Institute for Clinical Evaluative Sciences (ICES) key number 
Table 2 Cohort baseline characteristics, according to AEC service availability

\begin{tabular}{|c|c|c|c|c|c|}
\hline & $\begin{array}{l}\text { Fulltime } \\
\text { extended hours }\end{array}$ & $\begin{array}{l}\text { Part-time } \\
\text { extended hours }\end{array}$ & $\begin{array}{l}\text { Fulltime } \\
\text { regular hours }\end{array}$ & $\begin{array}{l}\text { Part-time } \\
\text { regular hours }\end{array}$ & No AEC access \\
\hline & $N=9857$ & $N=17780$ & $N=6365$ & $N=7699$ & $N=33353$ \\
\hline & n (\%) & n (\%) & n (\%) & n (\%) & n (\%) \\
\hline Male & 5052 (51.3\%) & 8993 (50.6\%) & $3044(47.8 \%)$ & 4017 (52.2\%) & $16491(49.4 \%)$ \\
\hline \multicolumn{6}{|l|}{ Age group (years) } \\
\hline $2-4$ & 2005 (20.3\%) & 3329 (18.7\%) & 847 (13.3\%) & 1956 (25.4\%) & 5392 (16.2\%) \\
\hline $5-9$ & 1671 (17.0\%) & 3055 (17.2\%) & 784 (12.3\%) & 1493 (19.4\%) & 5165 (15.5\%) \\
\hline $10-14$ & 972 (9.9\%) & 1762 (9.9\%) & $560(8.8 \%)$ & 794 (10.3\%) & $3336(10.0 \%)$ \\
\hline $15-19$ & 738 (7.5\%) & $1394(7.8 \%)$ & 585 (9.2\%) & $521(6.8 \%)$ & 2907 (8.7\%) \\
\hline $20-24$ & 835 (8.5\%) & $1534(8.6 \%)$ & $674(10.6 \%)$ & $541(7.0 \%)$ & 2831 (8.5\%) \\
\hline $25-29$ & 710 (7.2\%) & $1323(7.4 \%)$ & $587(9.2 \%)$ & 446 (5.8\%) & 2494 (7.5\%) \\
\hline $30-39$ & 1218 (12.4\%) & 2257 (12.7\%) & 1012 (15.9\%) & 865 (11.2\%) & 4725 (14.2\%) \\
\hline $40-55$ & 1708 (17.3\%) & $3126(17.6 \%)$ & 1316 (20.7\%) & 1083 (14.1\%) & 6503 (19.5\%) \\
\hline \multicolumn{6}{|l|}{ Income quintile } \\
\hline 1 (lowest) & 2244 (22.8\%) & 4893 (27.5\%) & 1735 (27.3\%) & $2200(28.6 \%)$ & 7826 (23.5\%) \\
\hline 2 & 2349 (23.8\%) & 4047 (22.8\%) & 1370 (21.5\%) & 1599 (20.8\%) & 6820 (20.4\%) \\
\hline 3 & $2383(24.2 \%)$ & 3301 (18.6\%) & 1220 (19.2\%) & 1336 (17.4\%) & 6466 (19.4\%) \\
\hline 4 & 1716 (17.4\%) & 2999 (16.9\%) & 1040 (16.3\%) & 1265 (16.4\%) & 6573 (19.7\%) \\
\hline 5 (highest) & 1150 (11.7\%) & 2511 (14.1\%) & 979 (15.4\%) & $1256(16.3 \%)$ & $5578(16.7 \%)$ \\
\hline Missing & $15(0.2 \%)$ & $29(0.2 \%)$ & $21(0.3 \%)$ & $43(0.6 \%)$ & $90(0.3 \%)$ \\
\hline Rural & $283(2.9 \%)$ & 519 (2.9\%) & 1333 (20.9\%) & $502(6.5 \%)$ & 6496 (19.5\%) \\
\hline \multicolumn{6}{|c|}{ Acuity at index event } \\
\hline \multicolumn{6}{|c|}{ Inpatient admission } \\
\hline & $2237(22.7 \%)$ & $3060(17.2 \%)$ & $722(11.3 \%)$ & $1145(14.9 \%)$ & $4865(14.6 \%)$ \\
\hline \multicolumn{6}{|c|}{ Highest acuity CTAS 1-2 ED Visit } \\
\hline & $2402(24.4 \%)$ & 3971 (22.3\%) & $1079(17.0 \%)$ & $1530(19.9 \%)$ & $5456(16.4 \%)$ \\
\hline \multicolumn{6}{|c|}{ Urgent acuity (CTAS 3) ED Visit } \\
\hline & $5218(52.9 \%)$ & 10749 (60.5\%) & $4564(71.7 \%)$ & $5024(65.3 \%)$ & $23032(69.1 \%)$ \\
\hline \multicolumn{6}{|c|}{ Any primary care services in previous 2 years } \\
\hline & $9232(93.7 \%)$ & $16996(95.6 \%)$ & $5851(91.9 \%)$ & $7286(94.6 \%)$ & 31535 (94.5\%) \\
\hline \multicolumn{6}{|c|}{ Pre-existing asthma } \\
\hline & $7653(77.6 \%)$ & $13819(77.7 \%)$ & $4796(75.3 \%)$ & $5774(75.0 \%)$ & $26323(78.9 \%)$ \\
\hline \multicolumn{6}{|c|}{ Specialist asthma visit in previous 2 years } \\
\hline & $5104(51.8 \%)$ & $9814(55.2 \%)$ & $2607(41.0 \%)$ & $4539(59.0 \%)$ & $16934(50.8 \%)$ \\
\hline \multicolumn{6}{|c|}{ Asthma admissions in previous 2 years } \\
\hline & $414(4.2 \%)$ & $641(3.6 \%)$ & $155(2.4 \%)$ & $286(3.7 \%)$ & $1021(3.1 \%)$ \\
\hline \multicolumn{6}{|c|}{ Asthma ED visits in previous 2 years } \\
\hline & $1390(14.1 \%)$ & $2735(15.4 \%)$ & $952(15.0 \%)$ & $1106(14.4 \%)$ & $4906(14.7 \%)$ \\
\hline \multicolumn{6}{|l|}{ Hospital type } \\
\hline Community & 8716 (88.4\%) & 13744 (77.3\%) & 4355 (68.4\%) & 5888 (76.5\%) & 25941 (77.8\%) \\
\hline Small & 845 (8.6\%) & $0(0 \%)$ & $272(4.3 \%)$ & $0(0 \%)$ & 3265 (9.8\%) \\
\hline Teaching & $296(3.0 \%)$ & $4036(22.7 \%)$ & 1738 (27.3\%) & $1811(23.5 \%)$ & 4147 (12.4\%) \\
\hline
\end{tabular}


Table 3 ED visit, hospital admission or death within 6 months for the asthma admission and ED cohorts, according to AEC service availability

\begin{tabular}{|c|c|c|c|c|c|}
\hline & $\begin{array}{l}\text { Fulltime/ } \\
\text { extended hours }\end{array}$ & $\begin{array}{l}\text { Part-time/ } \\
\text { extended hours }\end{array}$ & $\begin{array}{l}\text { Fulltime } \\
\text { regular hours }\end{array}$ & $\begin{array}{l}\text { Part-time } \\
\text { regular hours }\end{array}$ & No AEC \\
\hline \multicolumn{6}{|c|}{ Admission cohort } \\
\hline & $N=2237$ & $N=3060$ & $N=722$ & $N=1145$ & $N=4865$ \\
\hline \multicolumn{6}{|c|}{ ED visits for asthma within 6-36 months of index event } \\
\hline 0 & $1535(68.6 \%)$ & $1934(63.2 \%)$ & $441(61.1 \%)$ & $715(62.4 \%)$ & $3131(64.4 \%)$ \\
\hline 1 & $397(17.7 \%)$ & $580(19.0 \%)$ & $138(19.1 \%)$ & $216(18.9 \%)$ & $876(18.0 \%)$ \\
\hline $2+$ & $305(13.6 \%)$ & $546(17.8 \%)$ & $143(19.8 \%)$ & $214(18.7 \%)$ & $858(17.6 \%)$ \\
\hline \multicolumn{6}{|c|}{ Hospital admissions for asthma within 6-36 months of index event } \\
\hline 0 & 1917 (85.7\%) & $2624(85.8 \%)$ & $625(86.6 \%)$ & $968(84.5 \%)$ & $4143(85.2 \%)$ \\
\hline 1 & $232(10.4 \%)$ & $297(9.7 \%)$ & $61(8.4 \%)$ & $127(11.1 \%)$ & $489(10.1 \%)$ \\
\hline $2+$ & $88(3.9 \%)$ & $139(4.5 \%)$ & $36(5.0 \%)$ & $50(4.4 \%)$ & $233(4.8 \%)$ \\
\hline \multicolumn{6}{|c|}{ Any death between 6 and 36 months of index event } \\
\hline Yes & $12(0.5 \%)$ & $11(0.4 \%)$ & $*(<1 \%)$ & $12(1.0 \%)$ & $43(0.9 \%)$ \\
\hline \multicolumn{6}{|c|}{ ED cohort } \\
\hline & $N=7620$ & $N=14720$ & $N=5643$ & $N=6554$ & $N=28488$ \\
\hline \multicolumn{6}{|c|}{ ED visits for asthma within 6-36 months of index event } \\
\hline 0 & $6008(78.8 \%)$ & $11345(77.1 \%))$ & $4336(76.8 \%)$ & $5005(76.4 \%)$ & 22067 (77.5\%) \\
\hline 1 & $1072(14.1 \%)$ & $2050(13.9 \%)$ & $804(14.2 \%)$ & $950(14.5 \%)$ & $4042(14.2 \%)$ \\
\hline $2+$ & $540(7.1 \%)$ & $1325(9.0 \%)$ & $503(8.9 \%)$ & $599(9.1 \%)$ & $2379(8.4 \%)$ \\
\hline \multicolumn{6}{|c|}{ Hospital admissions for asthma within 6-36 months of index event } \\
\hline 0 & $7534(98.9 \%)$ & $14544(98.8 \%)$ & $5599(99.2 \%)$ & $6468(98.7 \%)$ & $28176(98.9 \%)$ \\
\hline 1 & $78(1.0 \%)$ & $159(1.1 \%)$ & $39(0.7 \%)$ & $76(1.2 \%)$ & $274(1.0 \%)$ \\
\hline $2+$ & $8(0.1 \%)$ & $17(0.1 \%)$ & * & $10(0.2 \%)$ & $38(0.1 \%)$ \\
\hline \multicolumn{6}{|c|}{ Any death between 6 and 36 months of index event } \\
\hline Yes & $29(0.4 \%)$ & $73(0.5 \%)$ & $28(0.5 \%)$ & $36(0.5 \%)$ & $116(0.4 \%)$ \\
\hline
\end{tabular}

*value suppressed due to small cell size.

supported funding. However, in this large, populationbased study, we found only a modest association between potential AEC access and reduced subsequent acute care use for asthma. ED patients with asthma with access to an AEC having fulltime and extended hours of service had lower rates of admissions and ED visits in the 6-36 months follow up period. Hospitalized asthma patients with access to inpatient asthma education had lower rates of readmission and ED visits. Almost half of patients with asthma had no AEC access at their hospital or ED.

The evidence for the benefits of asthma education exists in many studies [4-10,23-29]. Three Cochrane reviews associate educational interventions with lower risk of future ED visits and in some cases, hospital admissions for asthma along with other improvements in asthma-related health outcomes. A review of 32 single-centre studies of asthma in children by Wolf et al showed that asthma selfmanagement education programs had modest reductions in emergency room visits, with a more pronounced effect for those having moderate or severe disease [6]. Boyd et al., in their review of 17 trials related to children who attended the emergency department for asthma, reported a lower risk of repeat visits and hospital admissions when children received an educational intervention [7]. In a review of 15 trials, Gibson et al reported that for adults, optimal education in asthma self-management resulted in improvements in asthma outcomes [8].

In Ontario, access to care is not an issue of health insurance. However, other barriers to access to chronic disease programs have been identified [30,31]. Recommendations to address these include the need for programs to be provided at a local level, improving ease of access and extended hours so that patients do not need to leave work for care, reducing travelling times, and tailoring programs to local needs. Our findings that only extended hours for AECs are associated with improved outcomes provides empiric support for the need for flexible services.

The socio-economic gradient in rate of readmissions and ED revisits in our cohort suggests that other barriers to care exist in a universal healthcare system. Others have 
Table 4 Adjusted relative rate (95\% confidence interval (CI)) of asthma admission, ED visit or death within 6 to 36 months post index event for the asthma admission and ED cohorts, according to AEC service availability

\begin{tabular}{|c|c|c|}
\hline & $\begin{array}{l}\text { Admission cohort } \\
\mathrm{N}=12029 \\
\text { Relative rate } \\
(95 \% \mathrm{Cl})\end{array}$ & $\begin{array}{l}\text { ED cohort } \\
\mathrm{N}=63025 \\
\text { Relative rate } \\
(95 \% \mathrm{Cl})\end{array}$ \\
\hline \multicolumn{3}{|l|}{ Access to AEC } \\
\hline Fulltime extended hours & $0.87(0.71,1.08)$ & $0.78(0.69,0.90)$ \\
\hline Fulltime regular hours & $0.95(0.74,1.22)$ & $1.13(0.98,1.30)$ \\
\hline Part-time extended hours & $0.90(0.78,1.03)$ & $0.94(0.85,1.03)$ \\
\hline Part-time regular hours & $0.93(0.80,1.08)$ & $1.03(0.84,1.25)$ \\
\hline No AEC & 1.00 Reference & 1.00 Reference \\
\hline \multicolumn{3}{|l|}{ Sex } \\
\hline Male & $1.04(0.95,1.14)$ & $1.14(1.08,1.20)$ \\
\hline \multicolumn{3}{|l|}{ Age group (years) } \\
\hline $2-4$ & $0.57(0.47,0.69)$ & $0.93(0.85,1.02)$ \\
\hline $5-9$ & $0.51(0.41,0.63)$ & $0.81(0.74 .0 .90)$ \\
\hline $10-14$ & $0.48(0.39,0.58)$ & $0.69(0.63,0.76)$ \\
\hline $15-19$ & $0.87(0.68,1.11)$ & $0.93(0.84,1.04)$ \\
\hline $20-24$ & 1.00 Reference & 1.00 Reference \\
\hline $25-29$ & $0.78(0.62,0.98)$ & $0.91(0.82,1.00)$ \\
\hline $30-39$ & $0.95(0.74,1.23)$ & $0.89(0.81,0.98)$ \\
\hline $40-55$ & $0.66(0.53,0.83)$ & $0.86(0.79,0.94)$ \\
\hline \multicolumn{3}{|l|}{ Acuity at index event } \\
\hline CTAS 1-2 (Highest acuity) & Not applicable & $1.35(1.27,1.43)$ \\
\hline CTAS 3 & Not applicable & 1.00 Reference \\
\hline \multicolumn{3}{|l|}{ Income quintile } \\
\hline 1 (lowest) & $1.40(1.23,1.59)$ & $1.34(1.25,1.44)$ \\
\hline 2 & $1.29(1.13,1.46)$ & $1.18(1.10,1.27)$ \\
\hline 3 & $1.15(1.01,1.31)$ & $1.18(1.10,1.27)$ \\
\hline 4 & $1.06(0.94,1.20)$ & $1.01(0.94,1.07)$ \\
\hline 5 (highest) & 1.00 Reference & 1.00 Reference \\
\hline Missing & $1.72(1.07,2.77)$ & $0.92(0.64,1.32)$ \\
\hline Rural & $1.01(0.89,1.13)$ & $0.99(0.91,1.07)$ \\
\hline Core primary care services in previous 2 yrs. & $0.96(0.78,1.18)$ & $0.97(0.88,1.07)$ \\
\hline Previously diagnosed asthma & $1.35(1.21,1.50)$ & $2.19(2.01,2.38)$ \\
\hline Specialist asthma visit in previous 2 yrs. & $1.14(1.07,1.22)$ & $1.09(1.04,1.14)$ \\
\hline Asthma admissions in previous 2 yrs. & $1.90(1.67,2.16)$ & $1.52(1.35,1.72)$ \\
\hline Asthma ED visits in previous 2 yrs. & $2.47(2.29,2.67)$ & $2.71(2.53,2.89)$ \\
\hline \multicolumn{3}{|l|}{ Hospital type } \\
\hline Community & $1.01(0.84,1.22)$ & $1.26(1.12,1.43)$ \\
\hline Small & $0.82(0.62,1.08)$ & $1.4(1.18,1.66)$ \\
\hline Teaching & 1.00 Reference & 1.00 Reference \\
\hline
\end{tabular}


Table 5 Adjusted relative rate $(95 \%$ confidence interval (CI)) of asthma admission, ED visit or death within 6 to 36 months post index event for the asthma admission and ED cohorts, according to access to inpatient or ED asthma education

\begin{tabular}{ll}
\hline & $\begin{array}{l}\text { Adjusted Relative Rate* } \\
\text { (95\% confidence intervals) }\end{array}$ \\
\hline ED cohort & \\
Access to AE including in ED & $0.91(0.76,1.10)$ \\
Access to AEC but no AE in ED & $0.97(0.89,1.06)$ \\
$\quad$ No AEC & 1.00 Reference \\
Admission cohort & \\
$\quad \begin{array}{l}\text { Access to AE including } \\
\text { during hospitalization }\end{array}$ & $0.87(0.75,1.00)$ \\
$\begin{array}{l}\text { Access to AEC but no AE } \\
\text { during hospitalization }\end{array}$ & $0.95(0.84,1.07)$ \\
No AEC & 1.00 Reference
\end{tabular}

*Adjusted for age, gender, socioeconomic status, rural residence, history of prior asthma admissions, primary and/or specialist asthma care, and hospital type.

demonstrated the relationship of poor asthma outcomes to medication insurance and access to controller medications [32], and environmental triggers in the home [33] or work environment [34].

Our study is the first to study the effectiveness of asthma education programs including AEC program and service characteristics in a "real world" setting. Although our survey indicates that AECs in Ontario incorporate guideline-based recommendations for asthma education into their programs and use trained Certified Asthma Educators as the primary healthcare providers for patient education, our findings in the context of the evidence for asthma education suggest that barriers to access to asthma education services are an important issue.

Asthma is considered to be an ambulatory care sensitive condition, one where appropriate ambulatory care may prevent or reduce the need for admission to hospital [35-39]. This study focused on the potential for multi-modal asthma education to prevent acute exacerbations after an admission or high acuity ED visit. However, preventing these initial events is also important. Two Ontario studies demonstrated significant reductions in ED visits and improved asthma-related health outcomes for those receiving asthma self-management education from Certified Asthma Educators in primary care $[24,25]$. Over $90 \%$ of patients in our study were seen by primary care providers in the previous two years. This suggests there is the potential to further reduce asthma morbidity, as measured by the index events in our study, with self-management programs integrated into primary care. This could increase access to asthma education for those without local access to an AEC.
In the secondary analysis of AEC services at the time of the index event, the finding of effectiveness of inpatient compared with ED asthma education is noteworthy. Our study could not determine what proportion of patients actually had asthma education during their index event. However, our findings suggest that there may be specific issues delivering effective asthma education in an ED setting, such as the relatively short timeframe that patients will spend in the ED as compared with inpatients. Research suggests in-hospital asthma care can provide a key teachable moment, when patients and their caregivers have a stronger motivation to learn [40].

\section{Strengths and limitations of the study}

Strengths of this study include high survey response rates and population-based study of the effectiveness of AECs. The survey allowed definition of AEC services in a highly operational way that underscored differences in access to services while attesting to programs' alignment with guideline-based recommendations for asthma selfmanagement education.

The main limitations are related to our exposure of potential access to AECs since we were not able to ascertain which patients actually used these AEC services. Administrative data of attendance at AECs does not exist. In addition, patients identified as not having access could have attended an AEC at another institution. However, it was not our intent to evaluate asthma education at the individual patient level but to assess the potential benefit of these centres as currently implemented for their population of patients with acute asthma. It is also possible that hospitals that have AECs are different in other ways from those that do not. There may also be unmeasured confounding (patient or geographic). For instance, it is possible that some hospitals instituted AECs to address high regional rates of asthma or severe asthma due to local conditions such as high pollution. A higher proportion of patients with no AEC access live in rural areas, and there may be environmental differences that are related to disease severity or differing patterns of healthcare use that may explain our inconsistent findings around the benefit of AECs. We attempted to control for relevant patient and hospital characteristics but the observational nature of the study can point only to association and not causality.

\section{Conclusions}

AECs in Ontario incorporate guideline-based recommendations for asthma education into their programs and use trained Certified Asthma Educators as the primary healthcare providers for patient education. Extended hours of service and inpatient asthma education appear to be a necessary component for effective care but overall effects on subsequent acute care use are modest. Our study suggests that current implementation 
and funding of AECs should include review of both the effectiveness of, and access to, these services. Administrative records of AEC attendance would facilitate monitoring and evaluation of these services.

\section{Prior abstract presentation}

Canadian Respiratory Conference 2012, Vancouver BC, April 28, 2012.

American Thoracic Society International Conference, San Francisco CA, May 23, 2012.

INSPIRE 2012 Respiratory Therapy Society of Ontario Education Forum, Oakville ON, October 17, 2012.

Ontario Lung Association Better Breathing Annual Conference, Toronto ON, February 2, 2013.

\section{Abbreviations}

aRR: Adjusted relative rate; AEC: Asthma education centre; CTAS: Canadian triage assessment system; ED: Emergency department.

\section{Competing interests}

Nancy Garvey was an employee of the Ontario Ministry of Health and Long-Term Care as a Senior Program Consultant for Ontario's Asthma Program. This study began prior to her working for the Ministry and is independent of any work for the Ministry. The other authors declare that they have no competing of interest.

\section{Authors' contributions}

AG is the guarantor of this study. NG, PB, TS and AG conceived of the project. All authors made significant contributions to the design and interpretation of the study. JG and YL analysed the data. NG drafted the manuscript and all authors revised it critically. All authors have read and approved the final manuscript and are accountable for all aspects of the work

\section{Acknowledgments}

Funding was provided by an Emerging Team Grant (ETG92248) in Applied Health Services and Policy Research (ETG92248) from the Canadian Institutes of Health Research and by the Institute for Clinical Evaluative Sciences that is funded by an annual grant from the Ontario Ministry of Health and Long-Term Care. Astrid Guttmann receives salary support through an Applied Research Chair in Child Health Services Research from the Canadian Institutes of Health Research.

The authors acknowledge the help of staff at the Institute for Clinical Evaluative Sciences, Toronto, Ontario; Nancy MacCallum and Karen Cauch-Dudek for advice on electronic survey implementation and design; Nancy MacCallum and Sharon Thomas for their help with coordination of the 163 sites involved in the study; Marian Vermeulen for the Facility-Institution linkage to the survey database.

The Institute for Clinical Evaluative Sciences is a non-profit organization funded by the Ontario Ministry of Health and Long-Term Care with provision of population-based data. The opinions, results and conclusions reported in this paper are those of the authors and are independent from all funding sources. No endorsement by the Institute for Clinical Evaluative Sciences or the Ontario Ministry of Health and Long-Term Care is intended or should be inferred.
}

\footnotetext{
Author details

${ }^{1}$ Charles Sturt University, Wagga Wagga, New South Wales, Australia. ${ }^{2}$ Institute for Clinical Evaluative Sciences, Toronto, Ontario, Canada. ${ }^{3}$ Division of Paediatric Medicine, Hospital for Sick Children, Toronto, Ontario, Canada. ${ }^{4}$ Department of Paediatrics University of Toronto, Toronto, Ontario, Canada. ${ }^{5}$ Institute for Health Policy, Management and Evaluation, University of Toronto, Toronto, Ontario, Canada.
}

Received: 31 March 2014 Accepted: 24 October 2014

Published online: 13 November 2014

\section{References}

1. Brooks D, Dixon P, Fitch M, Goldstein R, Granton J, Holowaty E, Kovesi T, Lougheed D, Maleki-Yazdi MR, Nonoyama M, Pipe A, Ramsdale H, Selby P, Stanbrook M, Stieb D, Subbarao P, Tamari IE: Your lungs, your life: insights and solutions to lung health in Ontario 2011, RiskAnalytica, on behalf of the Ontario Lung Association, based on data from: Smetanin, P., Stiff, D., Briante, C., Ahmad, S., Ler, A., Wong, L. Life and Economic Burden of Lung Disease in Ontario: 2011 to 2041. Toronto, ON: Ontario Lung Association; 2011.

2. Global Initiative for Asthma, Global Strategy for Asthma Management and Prevention, Updated 2009, Chapter 4, Asthma Management and Prevention Programs, http://www.ginasthma.org/documents/5/documents_variants/35/ GINA-Report\%2C-Global-Strategy-for-Asthma-Management-and-Prevention2010, viewed November 13, 2010

3. National Asthma Education and Prevention Program Expert Panel Report 3: Guidelines for the Diagnosis and Management of Asthma Full Report 2007 National Institutes of Health. Washington DC: National Heart Lung and Blood Institute; 2007. NIH Publication No. 97-4051. August 28, 2007. Washington DC.

4. Lougheed MD, Lemière C, Dell SD, Ducharme FM, FitzGerald JM, Leigh R, Licskai C, Rowe BH, Bwie D, Becker A, Boulet L: Canadian Thoracic Society Asthma management continuum - 2010 consensus summary for children six years of age and over, and adults. Can Respir J 2010, 17(1):15-24.

5. Canadian Network for Respiratory Care website, About Us. http://cnrchome. net/aboutuswhoweare.html, accessed March 1, 2011.

6. Wolf F, Guevara JP, Grum CM, Clark NM, Cates CJ: Educational interventions for asthma in children. Cochrane Database Syst Rev 2002, 4:1-209.

7. Boyd M, Lasserson TJ, McKean MC, Gibson PG, Ducharme FM, Haby M: Interventions for educating children who are at risk of asthma-related emergency department attendance. Cochrane Database Syst Rev 2009, 2:1-120.

8. Gibson PG, Powell H, Wilson AJ, Abramson M, Haywood P, Bauman A, Hensley MJ, Walter EH. Self-management education and regular practitioner review for adults with asthma. Cochrane Database Syst Rev 2003(1): 1-84.

9. Hopman W, Garvey N, Olajos-Clow J, White Markham A, Lougheed MD: Outcomes of asthma education: Results of a multi-site evaluation. Can Respir J 2004, 11(4):291-295.

10. Walders N, Cercsmar C, Schluchter M, Redline S, Kirchner HL, Drotar D: An interdisciplinary intervention for undertreated pediatric asthma. Chest 2006, 129:292-299.

11. Kelly CS, Morrow AL, Shults J, Nakas N, Strope GL, Adelman RD: Outcomes evaluation of a comprehensive intervention program for asthmatic children enrolled in Medicaid. Pediatrics 2000, 105:1029-1035.

12. Tilly K, Garvey N, Gold M, Powell E, Proudlock M: Outcomes management and asthma education in a community hospital: ongoing monitoring of health status. Qual Manag Health Care 1996, 4(3):67-78.

13. Hwee J, Cauch-Dudek K, Chen Z, Ratnasingham S, Victor JC, Shah BR: The impact of diabetes education centre attendance on long-term clinical outcomes. Can J Diabetes 2012, 36:S21.

14. Kralj B. Measuring 'rurality' for purposes of health-care planning: an empirical measure for Ontario. Ontario Med Rev 2000: 1-20.

15. To T, Gershon A, Tassoudji M, Guan J, Wang C, Estrabillo E, Cicutto L: The burden of asthma in Ontario. In ICES Investigative Report. Toronto: Institute for Clinical Evaluative Sciences; 2006.

16. Gershon A, Wang C, Vasilevska-Ristovska J, Guan J, Cicutto L, To T: Identifying patients diagnosed with asthma using health administrative ata. AJRCCM 2008, 16(6):183-188.

17. Ungar W, Paterson M, Gomes T, Bikangaga P, Gold M, To T, Kozyrskyj AL: Relationship of asthma management, socioeconomic status, and medication insurance characteristics to exacerbation frequency in children with asthma. Ann Allergy Asthma Immunol 2011, 106:17-23.

18. Lougheed MD, Garvey N, Chapman KR, Cicutto L, Dales R, Day AG, Hopman WM, Lam M, Sears MR, Szpiro K, To T, Paterson NA: Variations and gaps in management of acute asthma in Ontario emergency departments. Chest 2009, 135:724-736.

19. Gershon AS, Wang C, Guan J, Vasilevska-Ristovska J, Cicutto L, To T: Identifying patients with physician-diagnosed asthma in health administrative databases. Can Respir J 2009, 16(6):183-188.

20. McCullagh P, Nelder JA: Generalized Linear Models. New York: Chapman \& Hall; 1989 
21. Zeger SL, Liang KY: Longitudinal data analysis for discrete and continuous outcomes. Biometrics 1986, 42:121-30.

22. SAS : (Statistical Analysis Software) for UNIX, version 9.2.1. Cary, NC: SAS Institute; 2004

23. Ebbinghaus S, Bahrainwala AH: Asthma management by an inpatient asthma care team. Pediatr Nurs 2003, 29(3):177-183.

24. To T, Cicutto L, Degani N, McLimont S, Beyene J: Can a community evidence-based asthma care program improve clinical outcomes? Med Care 2008, 46(12):1257-1266.

25. Licskai C, Sands T, Ong M, Paolatto L, Nicoletti I. Using a knowledge translation framework to implement asthma clinical practice guidelines in primary care. Int J Qual Health Care (2012) doi:10.1093/intghc/mzs043 First published online: August 14, 2012.

26. Castro M, Zimmermann NA, Crocker S, Bradley J, Leven C, Schechtman KB: Asthma intervention program prevents readmissions in high healthcare utilizers. Am J Respir Crit Care Med 2003, 168:1095-9.

27. Coffman JM, Cabana MD, Halpin HA, Yelin EH: Effects of asthma education on children's use of acute care services: a meta-analysis. Pediatrics 2008, 121:575-586. DOl: 10.1542/ped.2007-0113.

28. Watson WTA, Gillespie MN, Thomas N, Filuk SE, McColm J, Piwniuk MP, Becker AB: Small-group, interactive education and the effect on asthma control by children and their families. CMAJ 2009, 181(5):257-263.

29. Fleming K, Kuzik B, Chen C: Hospital-based inter-professional strategy to reduce in-patient admissions and emergency department visits for pediatric asthma. Healthc Q 2011, 14:47-51.

30. Jordan JE, Osborne RH: Chronic disease self-management education programs: challenges ahead. Med J Aus 2007, 186(2):84-87.

31. Chen J, Hou F: Unmet needs for health care. Health Reports 2002 13(2):23-34

32. Ungar WJ, Coyte PC: Prospective study of the patient-level cost of asthma care in children. Pediatr Pulmonol 2001, 32:101-108.

33. Takaro TK, Krieger J, Song L, Sharify D, Beaudet N: The breathe-easy home: the impact of asthma-friendly home construction on clinical outcomes and trigger exposure. Am J Public Health 2011, 101(1):55-62.

34. Vandenplas O, Toren K, Blanc PD: Health and socioeconomic impact of work-related asthma. Eur Respir J 2003, 22:689-697.

35. Bindman AB, Grumbach $K$, Osmand D, Komaromy M, Vranizan K, Lurie N, Billings J, Stewart A: Preventable hospitalizations and access to healthcare. JAMA 1995, 274(4):305-311. doi:10.1001/jama.1995.03530040033037.

36. Starfield B: Access-perceived or real, and to what? JAMA 1995, 274(4):346-347.

37. Ansari Z, Laditka JN, Laditka SB: Access to health care and hospitalization for ambulatory care sensitive conditions. Med Care Res Rev 2006, 63(6):719-741.

38. Institute for Healthcare Improvement, Improve Primary Care Access, http://www.hih.org/search/pages/results.aspx?k=Kabcenell+Al\%2C+Langley +J\%2C+Hupke+C.+Innovations+in+Planned+Care accessed November 12, 2012.

39. Health Council of Canada, Self-management support for Canadians with chronic health conditions: A focus for primary health care; May 2012. http://healthcouncilcanada.ca/rpt_det.php?id=372.

40. Lawson PJ, Flocke SA: Teachable moments for health behavior change: A concept analysis. Patient Educ Couns 2009, 76(1):25-30

\section{doi:10.1186/s12913-014-0561-x}

Cite this article as: Garvey et al:: The association of asthma education centre characteristics on hospitalizations and emergency department visits in Ontario: a population-based study. BMC Health Services Research 2014 14:561.

\section{Submit your next manuscript to BioMed Central and take full advantage of:}

- Convenient online submission

- Thorough peer review

- No space constraints or color figure charges

- Immediate publication on acceptance

- Inclusion in PubMed, CAS, Scopus and Google Scholar

- Research which is freely available for redistribution 